\title{
Effect of Vitamin D on Serum Fibroblast Growth Factor-23 and Cardiac Tissue Hydroxyproline Levels in Experimentally Induced Insulin Resistance Associated with Left Ventricular Hypertrophy in Rats
}

\author{
EMAN S. ABD EL-LATIF, M.Sc.; ROWIDA R. IBRAHIM, M.D.; AMAL A. BAALASH, M.D. and \\ SALWA M. ALMELIGY, M.D.
}

The Department of Medical Biochemistry, Faculty of Medicine, Tanta University, Egypt

\begin{abstract}
Background: Insulin resistance cardiomyopathy refers to functional and structural changes at the level of myocardium; independent of hypertension, coronary artery disease, or any other known cardiac diseases, leading to HF, with $\mathrm{LVH}$ as the main structural hall mark for it. Several factors have been documented in its pathogenesis; in obese insulin resistant FGF-23 a bone derived hormone can be involved .The role of vitamin $\mathrm{D}$, has gained much attention over the last years as a potential therapeutic agent for prevention of insulin resistance and its protective role against ventricular hypertrophy.
\end{abstract}

Aim of Study: Was to evaluate the potential effect of vitamin $\mathrm{D}$ as a protective factor against the development of LVH in experimentally induced insulin resistance in rats using the level of FGF-23 as a predictor and cardiac tissue hydroxyproline as a biomarker for cardiac affection.

Material and Methods: This study was conducted on 60 male albino rats divided randomly into four equal groups as follow group I (normal control group), group II (vitamin D treated control group), group III (high sucrose subjected group) and group IV (vitamin D co-treated high sucrose subjected group). In order to induce insulin resistance and cardiomyopathy both third and fourth groups were allowed to get free access to $35 \%$ sucrose as their drinking water for 16 weeks, during induction of insulin resistance cardiomyopathy by sucrose in the fourth group rats were co-treated by giving vitamin D orally in a dose $(1000 \mathrm{IU} / \mathrm{kg}$ ) dissolved in $1 \mathrm{ml}$ olive oil, given every other day by gavage for 12 weeks. At the end of the experiment blood samples were collected by cardiac puncture after ether anesthesia, chest and abdomen were opened and the heart was extracted. All groups were subjected to estimation of: Serum measurement of fasting glucose level using colorimetric assay and fasting insulin level by rat insulin ELISA kit to asses insulin resistance using (HOMA-IR index). Also, serum FGF-23 by rat FGF-23 ELISA kit as well as left ventricular tissue hydroxyproline content using colorimetric assay. Histopathological examination of the left ventricle specimens was done.

Correspondence to: Dr. Eman S. Abd El-Latif E-Mail: dr.eman.sobhy.ahmed@gmail.com
Results: There were statistically significant differences between group III compared to other groups (I, II, IV), regarding fasting serum glucose, serum insulin, HOMA-IR, serum FGF-23 hydroxyproline content of the left ventricle. These parameters were significantly increased in high sucrose subjected group compared to other groups. Also, histopathological study confirmed the biochemical findings.

Conclusion: Vitamin D helped to ameliorate metabolic derangement in IR and the associated left ventricular hypertrophy directly and through modifying FGF-23 levels.

Key Words: Insulin resistance - Cardiomyopathy - FGF-23 - Hydroxyproline.

\section{Introduction}

INSULIN resistance is a global health issue, in which muscle, liver and white adipose cells can't respond properly to insulin leading to impairment of glucose uptake with endogenous hepatic glucose production increment resulting in both fasting and postprandial hyperglycemia [1,2] .

Prevalence of insulin resistance has been rising steadily over the last several decades, this increase has occurred across every age, sex and race along with the increased incidence of obesity [3] . Obesity is considered to be the most important risk factor for insulin resistance [4].

Insulin resistance associated with many health problems, of which its hazards to the cardiovascular system including stroke, coronary artery disease and cardiomyopathy [5].

Insulin-resistant cardiomyopathy is defined as functional and structural changes at the level of myocardium; independent of hypertension, coronary artery disease, or any other known cardiac 
diseases, leading to heart failure (HF) [6]. Left ventricular hypertrophy $(\mathrm{LVH})$ is considered to be a cardinal feature for the diagnosis of hypertrophic cardiomyopathy [7], the degree of this hypertrophy can be evaluated by using left ventricular hydroxyproline content as an indicator [8].

Fibroblast growth factor -23 (FGF-23) is one of the endocrinal class of FGF family; it is produced in bone osteocytes [9]. It was found to be associated with markers of insulin resistance and left ventricular hypertrophy [10]. Leptin (a depot fat derived hormone) induces the expression of FGF-23 [11].

Vitamin D, one of the fat soluble vitamins which consist of a group of fat-soluble molecules with similarity to steroids, but with "broken" ring [12]. Vitamin D status is an excellent marker of good health, including positive associations with young age, normal body weight and a healthy lifestyle [13].

Beside its role in maintaining $\mathrm{Ca}+{ }^{2} \mathrm{PO}^{-4}$ homeostasis and bone health [14], it is likely to improve insulin action and sensitivity by stimulating expression of the insulin receptors and nuclear peroxisome proliferative activated receptor (PPAR) in peripheral tissues [15]. In pancreatic $\beta$ cells, it indirectly normalizes extracellular calcium thus ensuring calcium influx through cell membranes to increase insulin secretion and directly up regulating insulin gene expression [16]. Vitamin D has a cardioprotective role especially in response to injury, as it has anti-hypertrophic effect. Also it up regulates matrix metalloproteinase (MMP) proteins through VDR allowing cardiomyocyte remodeling in response to injury so promoting heart cell structure and function [17].

\section{Aim of the work:}

The aim of the present study was to evaluate the potential effect of vitamin $\mathrm{D}$ as a protective factor against the development of LVH in experimentally induced insulin resistance in rats using the level of FGF-23 as a predictor and cardiac tissue hydroxyproline as a biomarker for cardiac affection.

\section{Patients and Methods}

\section{A- Material:}

Animals:

\section{Experimental design:}

This study was conducted on 60 male albino rats of approximately (120-150)g body weight, which were obtained from experimental animal colony of Tanta University. During the whole period of the study (12 weeks), animals were housed in wire mesh cages and kept under constant environmental conditions (temperature $23 \pm 2^{\circ} \mathrm{C}$ and $12 / 12$ hours light/dark cycle).

Care of the animals as well as the experimental procedures was performed in Medical Biochemistry Department, Faculty of Medicine, Tanta University, Egypt during 2018, in accordance to the guidance of ethical committee of Medical Research (Approval code 31811/10/17).

The animals were allowed free access to water and standard rat chew, after being acclimatized for one week; animals were divided randomly into four equal groups each comprised 15 rats:

Group I (Control group): Rats in this group were allowed to receive tap (plain) water for drinking for 12 weeks.

Group II (vitamin D treated control group): Rats in this group were allowed to receive tap (plain) water for drinking and received vitamin $\mathrm{D}$ in a dose $(1000 \mathrm{IU} / \mathrm{kg})$ dissolved in $1 \mathrm{ml}$ olive oil, given every other day by oral gavage for 12 weeks.

Group III (high sucrose subjected group): Rats in this group were allowed to receive free access to $35 \%$ sucrose $(350 \mathrm{~g}$ of sucrose dissolved in $1 \mathrm{~L}$ tap (plain) water in their drinking water for 12 weeks [18]

Group IV (vitamin D co-treated high sucrose subjected group): Rats in this group were allowed to receive free access to $35 \%$ sucrose in their drinking water in addition to vitamin $\mathrm{D}$ in a dose $(1000 \mathrm{IU} / \mathrm{kg}$ ) dissolved in $1 \mathrm{ml}$ olive oil, given every other day by oral gavage for 12 weeks [19]

- Rats in all groups were served a standard rat chow.

- The weight was assessed weekly. At the end of the experiment (12 weeks), all rats were weighed and blood was collected via cardiac puncture under ether anesthesia, serum was collected in capped epindorff and stored at $20^{\circ} \mathrm{C}$ for determination of the biochemical parameters, the abdomen and thoracic cavity were opened and the heart was extracted for histopathological examination and preparation of tissue acid hydrolysate.

\section{Chemicals:}

Sucrose, vitamin D and most other chemicals were purchased from Sigma-Aldrich Chemicals (St. Louis, MO, USA). All chemicals were of high analytic grade. 


\section{B-Methods:}

$i$ - Induction of insulin resistance and cardiomyopathy: Insulin resistance and cardiomyopathy were induced in both third and fourth groups by allowing rats to get free access to $35 \%$ sucrose in their drinking water for 12 weeks [18].

ii- Treatment with vitamin D: During induction of insulin resistance and cardiomyopathy by sucrose in the fourth group, rats were co-treated by giving vitamin D orally in a dose (1000IU/ $\mathrm{kg}$ /day) dissolved in $1 \mathrm{ml}$ olive oil, given every other day by gavage for 12 weeks [19]. The final dosage of vitamin $\mathrm{D}$ was adjusted to each rat group according to any changes in body weight which were assessed weekly, to maintain similar dosage per kg body weight of rats over the entire period of study.

\section{Sampling:}

The blood was collected by cardiac puncture after ether anesthesia from all animal groups after overnight (10-12h) fasting.

\section{Serum separation:}

Blood samples were collected in non-coated tubes and allowed to clot at room temperature for 30 minutes. Then samples were centrifuged at 3354 $\mathrm{xg}$ for 10 minutes. Sera were separated and transferred to polypropylene epindorphs and stored at $-20^{\circ} \mathrm{C}$ until analysis.

\section{Tissue sampling:}

The abdomen and thoracic cavity were opened, the heart was removed and washed with ice cold saline. The excess saline was blotted by pieces of filter paper. The left ventricle was chilled on ice and divided into pieces, one piece was kept in $10 \%$ formalin solution and stained with hematoxylin and eosin stain (H. \& E. stain), then they were examined by light microscope for histopathological study. While, the remaining pieces were stored at $-80^{\circ} \mathrm{C}$ till used for preparation of left ventricular tissue acid hydrolysate.

\section{All groups were subjected to the following:}

A- Serum measurement of the following parameters:

Fasting glucose level using enzymatic colorimetric glucose oxidase method according to trinder, 1969 using a commercial kit supplied by BIOMED diagnostic company, Germany [20]

- Fasting insulin level by rat insulin ELISA kit using a commercially available kit (Catalogue number \#: 201-11-0708) obtained from Sun Red Biotechnology Co., Ltd, Shanghai, China [21,22]

- Insulin resistance was assessed using the homeostasis model assessment index for insulin resistance (HOMA-IR) using Matthew's equation as follow [23]

HOMA-IR =

Fasting instulin (mIu/L) x Fasting glucose (mg/dI) 405

- Fibroblast growth factor-23 by rat FGF-23 ELISA KIT using a commercially available kit (Catalogue number \#: 201-11-0171) obtained from Sun Red Biotechnology Co., Shanghai, China [24].

B- Left ventricular tissue hydroxyproline content: Preparation of left ventricular acid hydrolysate:

It was necessary first to liberate the hydroxyproline by hydrolyzing the peptides via acid hydrolysis, freeze-dried heart samples were weighed, then added $10 \mathrm{mg}$ tissue $/ \mathrm{ml} 6 \mathrm{M} \mathrm{HCl}$ in thick walled glass tubes and homogenized then heated for at $120^{\circ} \mathrm{C}$ in autoclave for $3 \mathrm{~h} \mathrm{[25]}$

Determination of left ventricular tissue hydroxyproline:

Principle:

Oxidation of hydroxyproline to pyrrole followed by coupling with p-dimethyl aminobenzaldhyde to give a red color which was then measured by colorimetry at $555 \mathrm{~nm}$ wave length [26]

\section{Assay procedure:}

To each tube containing $1 \mathrm{ml}$ of hydrolyzed samples and $1 \mathrm{ml}$ of the standards the following were added:

- $1 \mathrm{ml}$ of $0.05 \mathrm{M}$ copper sulphate and $1 \mathrm{ml}$ of $2.5 \mathrm{~N}$ $\mathrm{NaOH}$ then mix gently.

- Water bath at $40^{\circ} \mathrm{C}$ for 5 minutes.

- $1 \mathrm{ml}$ of $6 \% \mathrm{H}_{2} \mathrm{O} 2$ was added and mixed tube by tube well.

- Tubes left in water bath for 10 min more with mixing.

- Tubes cooled with tap water then $4 \mathrm{ml}$ of $3 \mathrm{~N}$ $\mathrm{H} 2 \mathrm{SO} 4$ and $2 \mathrm{ml}$ of the $5 \%$ p.Dimethylam- inobenzaldhyde were added then mixed well.

- The tubes were capped and kept in water bath at $70^{\circ} \mathrm{C}$ for $15 \mathrm{~min}$.

- Tubes cooled and measured against blank (containing all reagents in the test tube with no tissue hydrolysate or standard) at wave length $555 \mathrm{~nm}$ immediately using colorimeter. 


\section{C- Histopathological examination of the left ven-} tricle specimens to confirm the presence of LVH:

Formalin-fixed heart tissues were processed, five- $m$-hick paraffin sections were stained with haematoxylin and eosin (H\&E) and photomicrographs were taken at 40x magnification power.

\section{Statistical analysis:}

All results were expressed as means $\pm \mathrm{SD}$. Differences between groups were assessed by oneway analysis of variance (ANOVA), followed by a post hoc multiple comparison test. The association between the parameters was determined using the Pearson's correlation coefficient. A $p$-value $<0.05$ was considered statistically significant. Statistical analysis was performed using the SPSS version
20.0 statistical software package (SPSS Inc., Chicago, IL).

\section{Results}

Table (1) summarized the comparative statistics of studied parameters between all groups. Using the multiple comparison test (Tukey's test), there was a statistically significant difference among the studied groups. There was a statistically significant increases of fasting serum glucose, fasting serum insulin, HOMA-IR, FGF-23 and LV hydroxyproline content in group III(high sucrose subjected group) compared to other groups, vitamin D administration resulted in decrease of fasting serum glucose, fasting serum insulin, HOMA-IR, FGF-23 and LV hydroxyproline content when compared to high sucrose subjected group but was still showing a significant increase in HOMA-IR when compared to control groups.

Histopathological report on different studied groups:

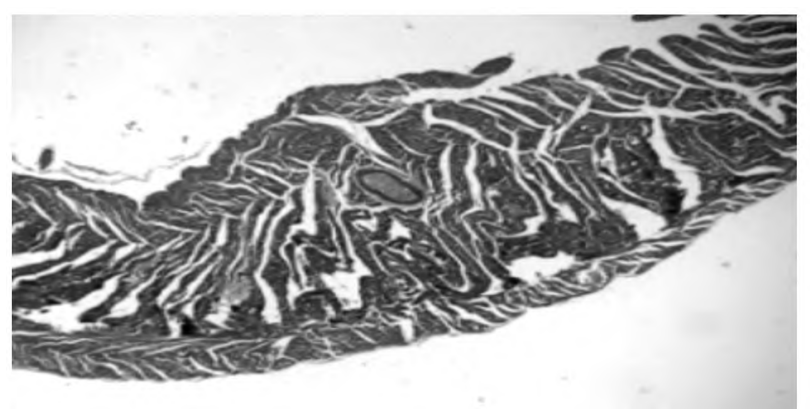

Fig. (A): Micrograph of (H. \& E. 40x) stained section from left ventricle. Group I (control group) with normal heart architecture and thickness of the LV wall.

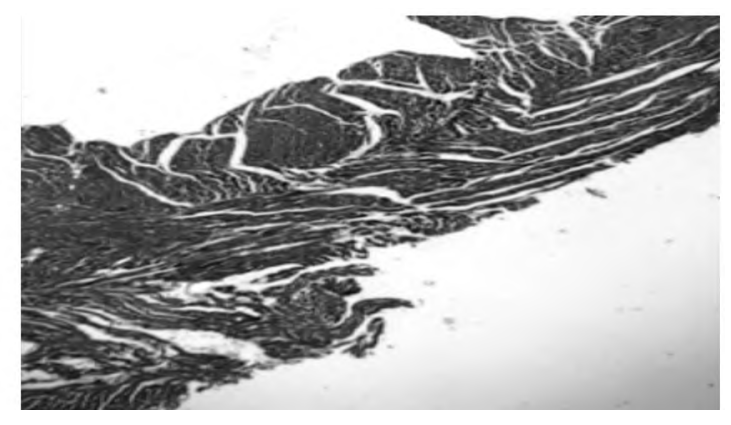

Fig. (B): Micrograph of (H. \& E. 40x) stained section from left ventricle. Group II (vitamin D treated control group) with normal heart architecture and thickness of the LV wall.

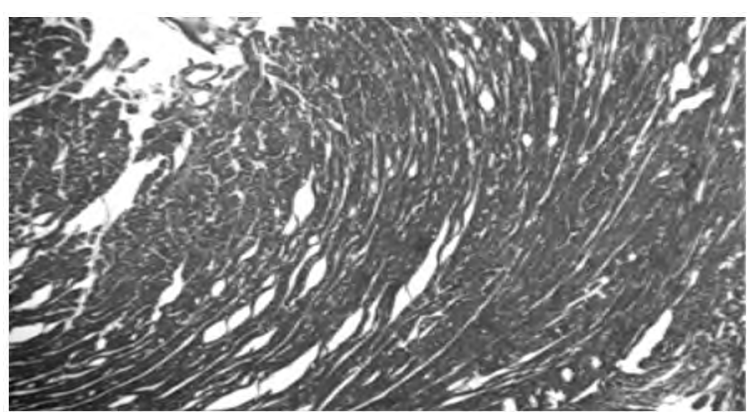

Fig. (C): Micrograph of (H. \& E. 40x) stained section from left ventricle. Group III (high sucrose subjected group) with showed obvious histopathological changes in the form of; markedly increased thickness of the LV wall with narrowed lumen.

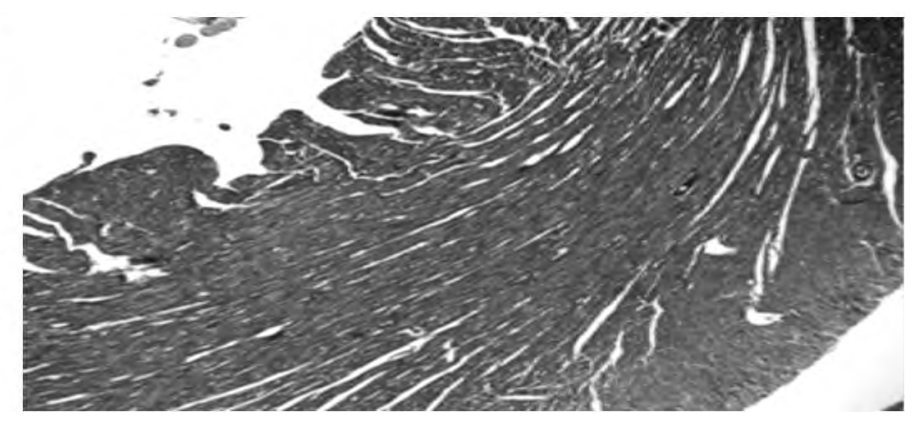

Fig. (D): Micrograph of (H. \& E. 40x) stained section from left ventricle. Group IV (vitamin D co-treated high sucrose subjected group) showed minimal histopathological changes in the form of minimal increase in the thickness of the LV wall. 
Table (1): Summarized the comparative statistics of studied parameters between all groups.

\begin{tabular}{|c|c|c|c|c|c|c|}
\hline & \multirow{2}{*}{$\begin{array}{c}(\text { Group I) } \\
(\mathrm{n}=15)\end{array}$} & \multirow{2}{*}{$\underset{(\mathrm{n}=15)}{(\text { Group II })}$} & \multirow{2}{*}{$\underset{(\mathrm{n}=15)}{(\text { Group III) }}$} & \multirow{2}{*}{$\begin{array}{c}(\text { Group IV) } \\
(\mathrm{n}=15)\end{array}$} & \multicolumn{2}{|c|}{ ANOVA } \\
\hline & & & & & F test & $p$-value \\
\hline Fasting blood Glucose (mg/dl) & $91.62 \pm 7.96 \mathrm{a}$ & $88.60 \pm 7.27 \mathbf{a}$ & $162.99 \pm 17.54 b$ & $117.83 \pm 12.82 \mathrm{c}$ & 120.418 & $0.001 *$ \\
\hline Hydroxyproline ( g/mg tissue) & $87.47 \pm 11.51$ & $92.33 \pm 11.27$ & $182.07 \pm 41.64$ & $108.87 \pm 11.39$ & 54.431 & $0.001 *$ \\
\hline Fibroblast growth factor-23 (pg/ml) & $109.93 \pm 9.00 \mathrm{a}$ & $124.60 \pm 37.69 \mathbf{a}$ & $263.33 \pm 82.98 \mathbf{b}$ & $142.73 \pm 38.64^{\mathbf{a}}$ & 29.830 & $0.001 *$ \\
\hline Insulin (mIU/L) & $0.84 \pm 0.16 \mathbf{a}$ & $0.74 \pm 0.12 \mathbf{a}$ & $10.11 \pm 1.20 \mathbf{b}$ & $2.65 \pm 0.67 \mathrm{c}$ & 755.517 & $0.001 *$ \\
\hline HOMA-IR & $0.19 \pm 0.05 \mathbf{a}$ & $0.16 \pm 0.04 \mathbf{a}$ & $4.07 \pm 0.97 \mathbf{b}$ & $1.04 \pm 0.12 \mathrm{c}$ & 213.026 & $0.001 *$ \\
\hline
\end{tabular}

Table (2): Correlation matrix between FGF-23 and (fasting serum glucose, HOMA-IR and LV hydroxyproline content) among all goups members.

\begin{tabular}{lcc}
\hline & $r$ & $p$ \\
\hline Fasting serum glucose & 0.864 & $0.001^{*}$ \\
HOMA-IR & 0.887 & $0.001^{*}$ \\
LV hydroxyproline content & 0.939 & $0.001^{*}$ \\
\hline
\end{tabular}

*Significant $p$-value $(<0.05)$.

\section{Discussion}

Insulin resistance occurs as a result of interplaying between a group of risk factors that may be modifiable as overweight/obesity, hypovitaminosis D, inflammation and smoking or nonmodifiable as age, ethnicity, gender, family history of T2DM, gestational diabetes and polycystic ovary syndrome [27].

To find out the precise cause behind the etiopathogenesis of this disease and to evaluate the potential drugs for treatment of insulin resistance associated complications as cardiomyopathy; various animal models were used [28]

In this study, insulin resistance has been induced in rats by keeping them on high sucrose hydration for 12 weeks.

These findings were supported by Kang et al., [29] and Saikrishna et al., [30] who provided an evidence that high-sucrose diet causes hepatic steatosis and exacerbates obesity with its metabolic complications, hyperglycemia, dyslipidemia, and hyperinsulinemia in rats.

Insulin resistance is always claimed when insulin fails to elicit a normal physiological response that is presented by hyperglycemia in face of normal or even higher insulin levels [31], which is confirmed by monitoring elevated (HOMA-IR) value [5].

In current study, rats kept on high sucrose hydration (group III) showed significant higher levels of fasting serum glucose, fasting serum insulin and (HOMA-IR) when compared to both control group (I,II) and vitamin D co-treated high sucrose subjected group (group IV).

These finding come in agreement with Pinto et al., [32] who stated that the exposure to high-sucrose diet was capable to induce insulin resistance and hyperinsulinemia. Furthermore, El-Hafidi et al., [33] showed that sucrose feeding decreases reduced glutathione (GSH) concentration and causes a consequent oxidative stress and insulin resistance in rats.

Insulin resistance represents a serious risk factor for the development of cardiovascular problems. Also, several studies have shown that insulin resistance is an independent predictor of cardiomyopathy and other cardiovascular diseases [6].

The pathological hallmarks in LVH are myocyte hypertrophy and disarray together with expansion of the interstitial collagen compartment leading to myocardial fibrosis these pathological changes were proved to be an important markers and determinant in the pathogenesis of hypertrophic cardiomyopathy [34]

Hydroxyproline represents an imino acid in the triple helix of collagen occupying Y position predominately [35]. Its concentration was validated by Ninh et al., [36] and others [26] to be used as an indicator for collagen content and thus used for determination of the degree of LV hypertrophy.

In the current study the level of hydroxyproline in LV acid hydrolysate was significantly higher in rats kept on high sucrose hydration (group III) when compared to both control groups (group I, II) and vitamin D co-treated high sucrose subjected group (group IV).

These findings coped with the results obtained by Panchal et al., [37] which revealed that highcarbohydrate high-fat diet-induced MetS and cardiovascular remodeling in rats which explained by cardiac steatosis and pro-inflammatory transcription factor NF- $\kappa \mathrm{B}$ contributing to over expression of 
collagen. Likewise Okatan et al., [38], highlighted the link between high carbohydrate intake, IR, MetS and cardiac hypertrophy, in part due to increased systemic oxidative stress with lipid deposition in the heart tissue.

In this study, there was a positive correlation between HOMA-IR levels and LV hydroxyproline in all groups which is considered as evidence to the role of high sucrose induced insulin resistance in the development of $\mathrm{LVH}$ in rats.

Many factors have been implicated in the pathogenesis of insulin resistance LVH [39]. But in this study, we put a spot on the role of FGF-23, a bone derived phosphaturic hormone that may be over secreted in cases of insulin resistance, even with normal kidney function [40]. It recently also has been emerged as important predictor for cardiovascular outcome both in terms of morbidity and mortality [41].

In the current study, rats kept on high sucrose hydration (group III) showed significant higher serum FGF-23 levels when compared to both control group (group I,II) and vitamin D co-treated high sucrose subjected group (group IV) with a positive significant correlation between serum FGF-23 and HOMA-IR levels.

The above mentioned findings were documented by He et al., [42] who revealed that serum FGF-23 levels were positively correlated with HOMA-IR, and obesity due to the stimulatory effects of adipokines on FGF-23 expression in bone. In addition, Hanks et al., [43] found that FGF-23 was significantly associated with higher inflammatory biomarkers, insulin resistance and LVH with greater risk of cardiovascular morbidity and mortality in both chronic renal disease patient and general population.

This may be explained by excess release of leptin which is an adipocyte-derived hormone, leptin was proved to markedly increase expression of bone FGF-23 [11]

Also, serum FGF-23 showed a positive significant correlation between it and LV hydroxyproline content.

In agreement Faul C. [44] who studied cardiac actions of FGF 23, most likely, the cardiac scenario depends on the nature of the mechanistic studies showing that FGF-23 can activate FGFR4 in the heart, FGF-23 appears to be a major driver of LVH.

Di Marco et al., [45] found that elevated levels of FGF-23 may exert $\alpha$ Klotho-independent effect on the heart, liver, and cells of the immune system.
These maladaptive effects may thereby contribute to cardiovascular disease, kidney disease progression and mortality.

On contrary to the results of the present study, Sit et al., [46] did not find any statistically significant relationship between IR and FGF-23 levels in MetS in his study that may be explained by insufficient number of study samples.

Elevated FGF-23 activates FGFR4 in the myocardium, making FGF-23 to be considered as a major driver of LVH, FGF-23 activates the PLC $\gamma /$ calcineurin/NFAT signaling axis in myocytes, promoting cardiac hypertrophy, whereas $\alpha$-klothoexpressing cells respond to FGF-23 by activating the Ras/MAPK cascade so it was found that the presence of $\alpha$-klotho is not a prerequisite for FGF23 responsiveness, indicates that the heart might be capable of directly responding to circulating FGF-23 [47].

In addition, FGF-23 acts to counter-regulate the effects of vitamin D on cardiovascular system which suggests playing an important role in $\mathrm{CV}$ related signaling pathways as elevated FGF-23 inhibits 1- $\alpha$ hydroxylase that transforms 25 -hydroxyvitamin D3 to active 1,25-dihydroxyvitamin D3, thereby acting as counter-regulatory hormone for vitamin D [48].

The aim of the present study was to evaluate the potential effect of vitamin $\mathrm{D}$ as a protective factor against the development of LVH in experimentally induced insulin resistance in rats using the levels of FGF-23 as a predictor and cardiac tissue hydroxyproline as a biomarker for cardiac affection.

The present study depicted that concomitant administration of vitamin D resulted in statistically significant decrease in the level of different biochemical parameters in group IV compared to group III, although it was still statistically higher than that of the control.

In accordance, Clemente-Postigo et al., [49] showed that low vitamin D levels are associated with obesity, IR and diabetes as vitamin D influences pancreatic $\beta$-cell function directly by binding to VDR. Also, Swami et al., [50] studies revealed that the beneficial effects of vitamin $\mathrm{D}$ are particularly effective in improving insulin resistance.

Vitamin D plays a physiological role in $\beta$-cells this is supported by the high expression of VDR [51]. In peripheral tissues, it is likely to improve insulin action directly by stimulating expression 
of the insulin receptors. In addition, it plays a role in insulin sensitivity by up regulating, nuclear Peroxisome proliferative activated receptor [52] In $\beta$-cells, it increases insulin secretion directly via stimulating the expression of the insulin gene, indirectly normalizes extracellular calcium thus ensuring calcium influx through cell membranes promoting insulin exocytosis [53]

Systemic inflammatory mediators affecting $\beta$ cells are also tackled by direct effect of vitamin D on cytokines. The mechanisms involved seem to be related to the inhibition of NF- $\kappa B$ pathway by VDRs [54]

A seasonal variation of glycemic control has been observed in healthy and type 2 diabetic individuals with worsening during winter and spring, indicating at least a partial role for vitamin D signaling in glucose homeostasis and T2DM [55]

Intriguingly, the present study proved that the concomitant administration of vitamin D results in statistically significant decrease in the level of LV hydroxyproline and serum FGF-23 confirmed by improvement of histopathological examination of the LV.

Leifheit-Nestler et al., [56] revealed the cardioprotective effects of calcitriol stem from its inhibitory actions on the cardiac FGF-23/FGFR4 system, and based on their counter balancing effects on cardiac myocytes. High FGF-23 and low calcitriol synergistically contribute to cardiac hypertrophy. Also, Al-Rasheed et al., [57] concluded that the administration of cholecalciferol markedly attenuated the development of cardiac hypertrophy likely through downregulation of TNF- $\alpha / N F-\kappa B / p 65$ signaling pathways.

Vit D may play an important role in improving IR and LVH. The cardio-protective role of vitamin $\mathrm{D}$ may be explained by up regulating matrix metalloproteinase (MMP) proteins in VDR, which contribute to cardiomyocyte remodeling in response to injury, also, it has anti-hypertrophic effect through down-regulation of hyperotrophy genes, thus indicating the role of vitamin D in maintaining heart cell structure and function, also through improvement of insulin sensitivity and secretion [17].

On contrast, Santos et al., [58] said that normal rats supplemented with vitamin $\mathrm{D}$ showed concentric cardiac hypertrophy, this controversy may be explained by using high toxic doses of the vitamin in his study.

\section{Conclusion:}

From this study we can conclude that vitamin D supplementation to high sucrose diet fed animals helped to ameliorate left ventricular hypertrophy, this is partially through reducing the levels of FGF23 and through improving the metabolic derangement of insulin resistance, as well as its direct antihypertrophic, cardioprotective effect.

\section{References}

1- CZECH M.: Insulin action and resistance in obesity and type 2 diabetes. Nature Medicine, 23 (7): 804-814, 2017.

2- ROGOWICZ-FRONTCZAK A., MAJCHRZAK A. and ZOZULIN'SKA-ZIÓE KIEWICZ D.: Insulin resistance in endocrine disorders - treatment options. Endokrynol. Pol., 334-342, 2017.

3- CASTRO A.V.B., KOLKA C.M., KIM S.P., et al.: Obesity, insulin resistance and comorbidities-Mechanisms of association. Arq. Bras. Endocrinol. Metab., 58 (6): 600609,2014

4- GAGGINI M., CARLI F., ROSSO C., et al.: Altered amino acid concentrations in NAFLD: Impact of obesity and insulin resistance. Hepatology, 67 (1): 145-158, 2018.

5- GERSTEIN H.C., FERRANNINI E., RIDDLE M.C., et al.: Insulin resistance and cardiovascular outcomes in the origin trial. Diabetes. Obes. Metab., 20: 564-570, 2018.

6- JIA G., DEMARCO V.G. and SOWERS J.E.: Insulin resistance and hyperinsulinaemia in diabetic cardiomyopathy. Nat. Rev. Endocrinol., 12 (3): 144-153, 2016.

7- ALMORÓS A.L., TUÑÓN J., OREJAS M., CORTÉS M., et al.: Diagnostic approaches for diabetic cardiomyopathy. Cardiovascular Diabetology, 16: (28) 1-14, 2017.

8- CAO Y., HE Z., ZHU M., et al.: Sevoflurane inhibits cardiac function in pulmonary fibrosis mice through the TLR4 signaling pathway. Pulmonary Circulation, 8 (4) $1-7,2018$

9- MALGORZEWICZ S., WOLOSZYK P., CHAMIENIA A., et al.: ADMA and FGF-23 in relation to nutritional status in kidney transplant recipients. Transplantation, 102: 564-573, 2018.

10- URSEM S.R., VERVLOET M.G. and BÜTTLERETAL R.M.: The interrelation between FGF23 and glucose metabolism in humans. Journal of Diabetes and its Complications, 32 (9): 845-850, 2018.

11- TSUJI K., MAEDA T., KAWANE T., et al.: Leptin stimulates fibroblast growth factor 23 expression in bone and suppresses renal $\alpha 1,25$-dihydroxyvitamin D3 synthesis in leptin-deficient ob/ob Mice. Journal of Bone and Mineral Research, 25 (8): 1711-1723, 2010.

12- REBOLLEDO B.J., BERNARD J.A., WERNER B.C., et al.: The association of vitamin D status in lower extremity muscle strains and core muscle injuries at the national football league combine. Arthroscopy: The Journal of Arthroscopic \& Related Surgery, 34 (4): 1280-1285, 2018.

13- VAN SCHOOR N.M., HEYMANS M.W. and LIPS P.: Vitamin D status in relation to physical performance, falls and fractures in the Longitudinal Aging Study Amsterdam: A reanalysis of previous findings using standardized 
serum 25-hydroxyvitamin D values. The Journal of Steroid Biochemistry and Molecular Biology, 177: 255-260, 2018.

14- HANSEN T.H., MADSEN M.T.B., JØRGENSEN N.R., et al.: Bone turnover, calcium homeostasis, and vitamin D status in Danish vegans. European Journal of Clinical Nutrition, 72: 1046-1054, 2018.

15- BENETTI E., MASTROCOLA R., CHIAZZA F., et al.: Effects of vitamin $D$ on insulin resistance and myosteatosis in diet-induced obese mice. PLoS ONE, 13 (1): 1-19 2018.

16- ACHARYA A. and HALEMANI S.S.: Role of vitamin D in diabetes mellitus. IJPSR, 7 (5): 1881-1888.

17- TREHAN N., AFONSO L., LEVINE D.L., et al.: Vitamin D deficiency, supplementation, and cardiovascular health. Crit. Pathw. Cardiol., 109-120, 2017.

18- MANUELA A.B., CERQUEIRA B.G., VARELA-RODRÍGUEZ M., et al.: Glucose and lipid dysmetabolism in a rat model of prediabetes induced by a high-sucrose diet. Nutrients, 1-17, 2017.

19- FARHANGI M.A., NAMENI G., HAJILUIAN G., et al.: Cardiac tissue oxidative stress and inflammation after vitamin $\mathrm{D}$ administrations in high fat- diet induced obese rats. BMC Cardiovascular Disorders, 17: 1-7, 2017.

20- TRINDER P.: Determination of blood glucose using an oxidase-peroxidase system with a non-carcinogenic chromogen. J. Clin. Pathol., 22 (2): 158-161, 1969.

21- CHEUNG A.T., DAYANANDAN B., LEWIS J.T., et al.: Glucose-dependent insulin release from genetically engineered K cells. Science, 290 (5498): 1959-62, 2000.

22- DUTTAROY A., ZIMLIKI C.L., GAUTAM D., et al.: Muscarinic stimulation of pancreatic insulin and glucagon release is abolished in $\mathrm{m} 3$ muscarinic acetylcholine receptor-deficient mice. Diabetes, 53 (7): 1714-20, 2004.

23- MATTHEWS D.R., HOSKER J.P., RUDENSKI A.S., et al.: Homeostasis model assessment: Insulin resistance and beta-cell function from fasting plasma glucose and insulin concentrations in man. Diabetologia., 28 (7): 4129, 1985.

24- GLOSSE P., FAJOL A., HIRCHE F., et al.: A high-fat diet stimulates fibroblast growth factor 23 formation in mice through TNFa upregulation. Nutrition and Diabetes, 8: (36) 1-6, 2018.

25- EDWARDS C.A. and O'BRIEN W.D.: Modified assay for determination of hydroxyproline in a tissue hydrolysate. Clinica. Chimica. Acta., 104: 161-167, 1980.

26- LEACH A.A.: Notes on a Modification of the Neuman \& Logan Method for the determination of the Hydroxyproline. Biochem. J., 74: 70-71, 1960.

27- TORO-HUAMANCHUMO C.J., URRUNAGA-PASTOR D., GUARNIZO-POMA M., et al. (2019): Triglycerides and glucose index as an insulin resistance marker in a sample of healthy adults. Diabetes \& Metabolic Syndrome: Clinical Research \& Reviews, 13 (1): 272-277, 1960.

28- BARBOSA-DA-SILVA S., SARMENTO I.B. and LONZETTI-BARGU T.C.: Animal models of nutritional induction of type 2 diabetes mellitus. Int. J. Morphol., 32 (1): 279-293, 2014.

29- KANG I., CARR T. and CHUNG S.: Ellagic acid supplementation attenuates sucrose-induced obesity and meta- bolic complication in C57BL/6 mice. The FASEB Journal; 32 (11): 5761-6354, 2015.

30- SAIKRISHNA K., KUMARI R. and CHAITANYA K.: Combined administration of monosodium glutamate and high sucrose diet accelerates the induction of type 2 diabetes, vascular dysfunction, and memory impairment in rats. Journal of Environmental Pathology, Toxicology and Oncology, 37: 63-80, 2018.

31- HWANG J., STEIN D.T., BARZILAI N., et al.: Increased intrahepatic triglyceride is associated with peripheral insulin resistance: In vivo MR imaging and spectroscopy studies. American Journal of Physiology-Endocrinology and Metabolism, 293 (6): E1663-E1669, 2007.

32- PINTO B.A.S., MELO T.M., FLISTER K.F.T., et al.: Sustained exposure to high-sucrose diet triggers endoplasmic reticulum stress in hippocampus and anticipates cognitive and motor impairments in adults rats. The FASEB Journal, 31: 1000-1091, 2017.

33- EL-HAFIDI M., FRANCO M., RAMÍREZ A.Z., et al.: Glycine increases insulin sensitivity and glutathione. Biosynthesis and protects against oxidative stress in a model of sucrose-induced insulin resistance. Oxidative Medicine and Cellular Longevity, 1-12, 2018.

34- ZHAI M., LIU Z., ZHANG B., et al.: Melatonin protects against the pathological cardiac hypertrophy induced by transverse aortic constriction through activating PGC-1 p In vivo and in vitro studies. The Journal of Pineal Research, 63 (3): 1-18, 2017.

35- GUOYAO WU, LI P., WU G. and PENG L.I.: Roles of dietary glycine, proline, and hydroxyproline in collagen synthesis and animal growth. Amino Acids, 50 (1): 29$38,2018$.

36- NINH V.K., EL-HAJJ E.C., MOUTON A.J., et al.: Chronic ethanol administration prevents compensatory cardiac hypertrophy in pressure overload. Alcoholism: Clinical and Experimental Research, 42 (8):1409-1417, 2018.

37- PANCHAL S., POUDYAL H., IYER A., et al.: Highcarbohydrate, high-fat diet-induced metabolic syndrome and cardiovascular remodeling in rats. Journal of Cardiovascular Pharmacology, 57 (5): 611-24, 2011.

38- OKATAN E.N., KIZIL S., GOKTURK H., et al.: Highcarbohydrate diet-induced myocardialremodelling in rats. Curr. Res. Cardiol., 2 (1): 5-10, 2015.

39- PALOMER X., PIZARRO-DELGADO J. and VÁZQUEZCARRERA M.: Emerging actors in diabetic cardiomyopathy: Heartbreaker biomarkers or therapeutic targets? TIPS Trends in Pharmacological Sciences TIPS, 39 (5): 452-467, 2018.

40- ZAHEER S., DE BOER I.H., ALLISON M. et al.: Fibroblast growth factor 23, mineral metabolism, and adiposity in normal kidney function. The Journal of Clinical Endocrinology \& Metabolism, 102 (4): 1387-1395, 2017.

41- POELZL G., TRENKLER C., KLIEBHAN J., et al.: FGF23 is associated with disease severity and prognosis in chronic heart failure. European Journal of Clinical Investigation, 44 (12): 1150-1158, 2014.

42- HE X., SHEN Y., MA X., et al.: The association of serum FGF23 and non-alcoholic fatty liver disease is independent of vitamin D in type 2 diabetes patients Clinical \& exper- 
imental pharmacology and physiology. Clin. Exp. Pharmacol. Physiol., 45: 668-674, 2018.

43- HANKS L.J., CASAZZA K., JUDD S.E., et al.: Associations of fibroblast growth factor-23 with markers of inflammation, insulin resistance and obesity in adults. PLoS One, 10 (3): 1-12, 2015.

44- FAUL C.: Cardiac actions of fibroblast growth factor 23. Bone, 100: 69-79, 2017.

45- DI MARCO G.S. and BRAND M.: Off-target effects and adverse outcomes of fibroblast growth factor 23 in chronic kidney disease. Port. J. Nephrol. Hypert., 32 (1): 57-63, 2018.

46- SIT D., TANRıVERDI E., KAYABASI H., et al.: Is FGF23 effective on insulin resistance in individuals with metabolic syndrome? Hormone Molecular Biology and Clinical Investigation, 35 (2): 1-9, 2018.

47- MAHMOOD L.A.G., AL-SAADI R. and MATTHEWS L.: Vitamin D deficiency and cardiometabolic syndrome: Is the evidence solid?. Arch. Med. Health Sci., 5 (2): 229236, 2017.

48- HAN X. and QUARLES L.D.: Multiple faces of FGF-23. Curr. Opin. Nephrol. Hypertens., 25 (4): 333-342, 2016.

49- CLEMENTE-POSTIGO M., MUÑOZ-GARACH A., SERRANO M., et al.: Serum 25-hydroxyvitamin D and adipose tissue vitamin $\mathrm{D}$ receptor gene expression: relationship with obesity and type 2 diabetes. The Journal of Clinical Endocrinology \& Metabolism., 100 (4): E591E595, 2015.

50- SWAMI S., KRISHNAN A.V., WILLIAMS J., et al.: Vitamin D mitigates the adverse effects of obesity on breast cancer in mice. Endocrine-Related. Cancer, 23 (4): 251-264, 2016.

51- LEE A.C., TRIVEDI M. and BRANTON A.: The potential benefits of biofield energy treated vitamin D3 on bone mineralization in human bone osteosarcoma cells (MG-
63). International Journal of Nutrition and Food Sciences., 7 (1): 30-38, 2018.

52- TING-ILEE, KAO Y.H., CHEN YC., et al.: Cardiac metabolism, inflammation, and peroxisome proliferatoractivated receptors modulated by 1,25-dihydroxyvitamin D3 in diabetic rats. International Journal of Cardiology, 176 (1): 151-157, 2014.

53- WALLBAUM P., ROHDE S. and EHLERS L.: Antifibrogenic effects of vitamin $\mathrm{D}$ derivatives on mouse pancreatic stellate cells. World. J. Gastroenterol., 24 (2): 170-178, 2018.

54- SOARES M.J., PANNU P.K., CALTON E.K., et al.: Vitamin D status and calcium intake in systemic inflammation, insulin resistance and the metabolic syndrome: An update on current evidence. Trends in Food Science \& Technology, 62: 79-90, 2017.

55- RAFIQ S. and JEPPESEN P.: Is hypovitaminosis D related to incidence of Type 2 diabetes and high fasting glucose level in healthy subjects: A systematic review and metaanalysis of observational studies. Nutrients, 10 (1): 5966, 2018.

56- LEIFHEIT-NESTLER M., GRABNER A., HERMANN L., et al.: Vitamin D treatment attenuates cardiac FGF23/ FGFR4signaling and hypertrophy in uremic rats. Nephrol. Dial. Transplant., 32: 1493-1503, 2017.

57- AL-RASHEED N.M., BASSIOUNI Y.A., et al.: Vitamin $\mathrm{D}$ attenuates pro-inflammatory TNF- a cytokine expression by inhibiting NF-icB/p65 signaling in hypertrophied rat hearts. Journal of Physiology and Biochemistry, 71: (2)19, 2015.

58- SANTOS P.P., RAFACHO B. and ANDRÉA GONÇALVES A.: Vitamin D supplementation for four months causes cardiac hypertrophy and diastolic dysfunction in normal rats. The 01FASAB Journal Nutrition, 27 (1): 115, 2013. 


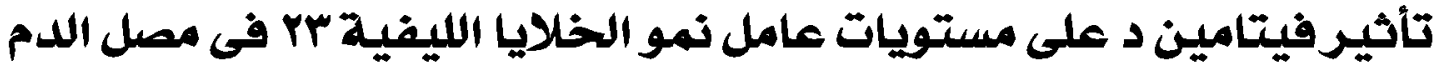

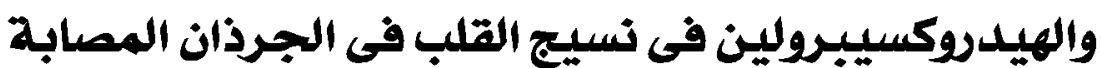

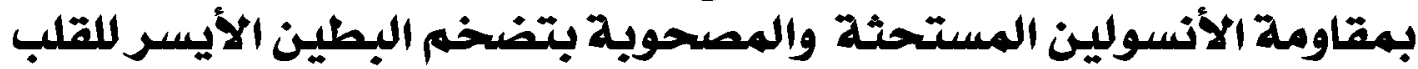

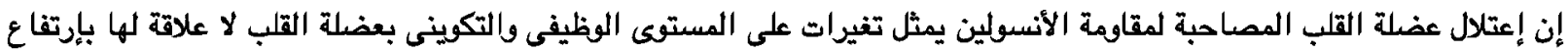

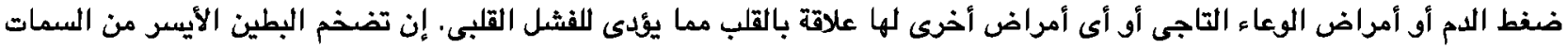

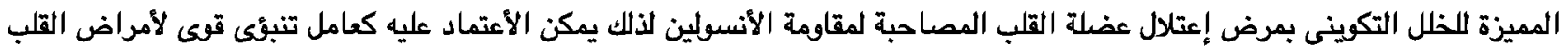

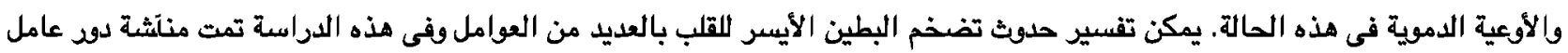

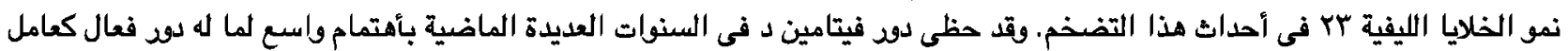
وقائى وعلاجى لحالات مقاومة الأنسولين وكذلك حالات تضخم البطين الأيسر للقلب.

إن الهدف من الدراسة هو إلقاء الضوء على التيجة المحتملة لفيتامين د على عامل نمو الخلايا الليفية بr فى مصل الدم والهيدروكسييرولين في نسيج القلب الجرذان المصابة بمقاومة الأنسولين المستحثة والمصحوبة بتضخم البطين الأيسر اللقلب.

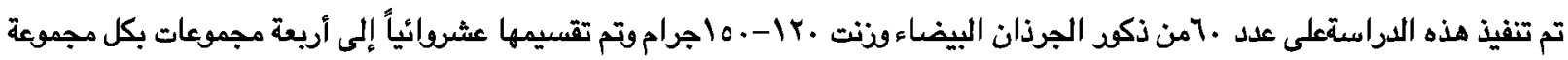

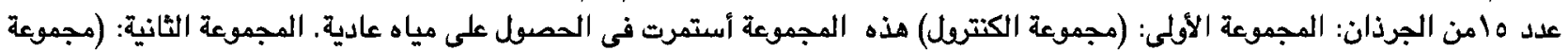

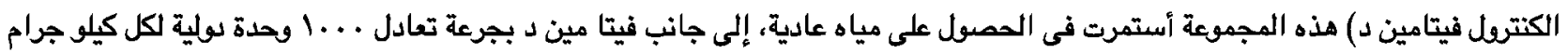



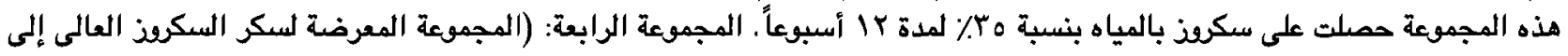

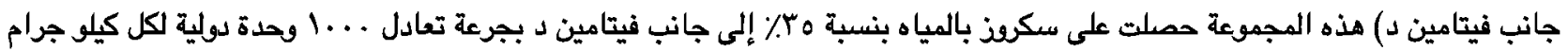
يتم إذابتها فى امللى زيت زيتون وإعطائها عن طريق الفم بالتزقيم كل يوم اخر.

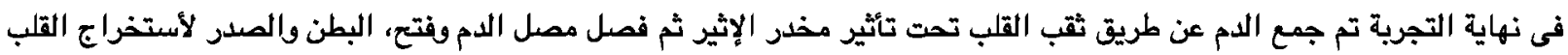

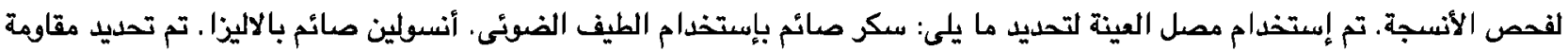


لنسيج البطين الأيسر للقلب.

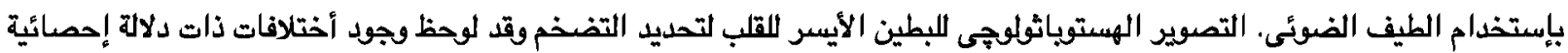

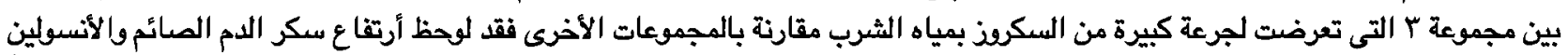

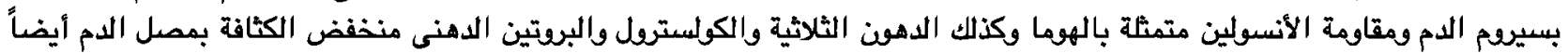

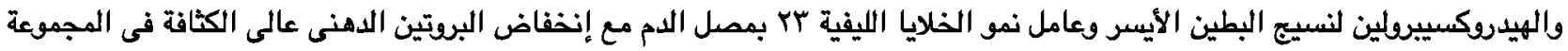

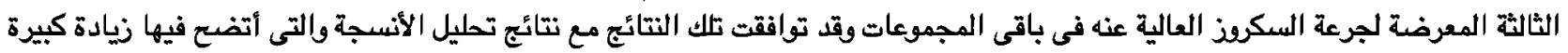

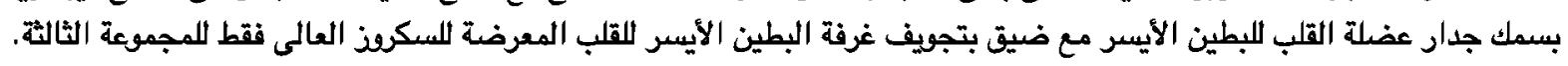

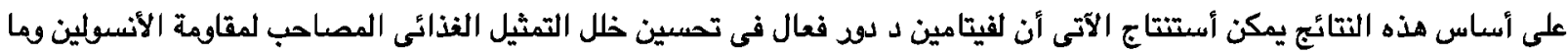

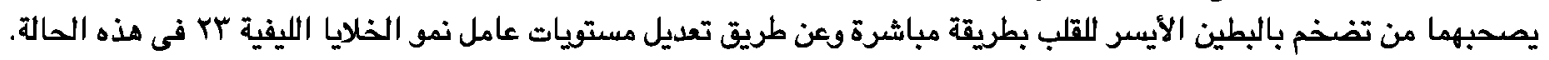

